\title{
Do the Reasons for Ceramic-on-ceramic Revisions Differ From Other Bearings in Total Hip Arthroplasty?
}

\author{
Henri Migaud MD, Sophie Putman MD, Grégory Kern MD, Ronald Isida MD, \\ Julien Girard MD, PhD, Nassima Ramdane PhD, Christian P. Delaunay MD, \\ Moussa Hamadouche MD, PhD, The SoFCOT Study Group
}

Published online: 2 June 2016

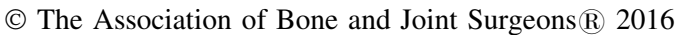

\begin{abstract}
Background Despite widespread use of ceramic-on-ceramic $(\mathrm{CoC})$ in total hip arthroplasty (THA) during the past 10 years, little is known about why revisions are performed in hips with this bearing or the time elapsed before revision.

Questions/purposes The purposes of this study were: (1) Do the reasons for first revision differ between $\mathrm{CoC}$ bearings and other bearing couples? (2) Does the time to
\end{abstract}

The institution of one or more of the authors (CPD) has received, during the study period, funding from the Société Française de Chirurgie Orthopédique et Traumatologique (SoFCOT, Paris, France).

Each author certifies that he or she, or a member of his or her immediate family, has no funding or commercial associations (eg, consultancies, stock ownership, equity interest, patent/licensing arrangements, etc) that might pose a conflict of interest in connection with the submitted article.

All ICMJE Conflict of Interest Forms for authors and Clinical Orthopaedics and Related Research ${ }^{\mathbb{R}}$ editors and board members are on file with the publication and can be viewed on request.

Clinical Orthopaedics and Related Research ${ }^{\mathbb{R}}$ neither advocates nor endorses the use of any treatment, drug, or device. Readers are encouraged to always seek additional information, including FDAapproval status, of any drug or device prior to clinical use.

Each author certifies that his or her institution approved the human protocol for this investigation, that all investigations were conducted in conformity with ethical principles of research, and that informed consent for participation in the study was obtained.

This work was performed at Hôpital Salengro, Lille University Hospital, Lille, France.

The SoFCOT Group: Jean-Noël Argenson MD, PhD, Department of Orthopaedic Surgery, APHM, Institute for Locomotion, SainteMarguerite Hospital, Marseille, France; Philippe Beaufils MD, Orthopaedic Department, Centre Hospitalier de Versailles, VersaillesSaint Quentin University, Le Chesnay, France; Jacques Bejui-Hugues MD, Department of Orthopedic Surgery, Pavillon T, Hôpital Edouard Herriot, Lyon, France; Marc Blaysat MD, Academic Department of Orthopaedic Surgery and Sports Trauma, CHU de Grenoble Teaching revision differ between $\mathrm{CoC}$ and other bearing couples? (3) Are there unique reasons for revisions of $\mathrm{CoC}$ bearings? Methods All members of the Société Française de Chirurgie Orthopédique et Traumatologique (SoFCOT) who performed $\geq 30$ revisions per year were invited to participate in this multicenter, prospective, observational study. Our data represent $12 \%$ of the revision procedures performed in France. A total of 2107 first revisions of THA (from January

Hospital Center, South District Hospital, Échirolles, France; Alexandre Bocéno MD, Clinique Chirurgicale de Chirurgie Orthopédique et Traumatologique, Nantes, France; Stéphane Boisgard MD, PhD, Chirurgie Orthopédique et Traumatologique, Hôpital Gabriel Montpied, Clermont Ferrand, France; François Bonnomet MD, PhD, Service de chirurgie orthopédique et de traumatology, Hôpital de Hautepierre, Hôpitaux universitaires de Strasbourg, Strasbourg, France; Bertrand Boyer MD, Service d'orthopédie et traumatologie, Hôpital Nord, Saint-Priest en Jarez, France; Jean-Paul Carret MD, PhD, Department of Orthopedic Surgery, Pavillon T, Hôpital Edouard Herriot, Lyon, France; Alain Cazenave MD, PhD, Institut Calot, Berck Sur Mer, France; JeanPierre Courpied MD, Hôpital Cochin, APHP, Université Paris 5, Paris, France; Loys Descamps MD, Clinique Saint-George Nice, France; Stéphane Descamps MD, PhD, Chirurgie Orthopédique et Traumatologique, Hôpital Gabriel Montpied, Clermont Ferrand, France; Romain Desmarchelier MD, Hospices Civils de Lyon, Centre Hospitalier Lyon-Sud, Service de Chirurgie Orthopédique Traumatologique et de Médecine du Sport, Centre Hospitalier Lyon Sud, Pierre-Bénite Cedex, France; Franck Dujardin MD, PhD, Department of Orthopaedic and Traumatology, CHU Charles-Nicolle, Rouen, France; Alain Duhamel PhD, Université Lille Nord de France, Lille, France, and Pôle de santé publique, laboratoire de biostatistique, CHRU de Lille, Lille, France; Matthieu Ehlinger $\mathrm{MD}, \mathrm{PhD}$, Service de chirurgie orthopédique et de traumatology, Hôpital de Hautepierre, Hôpitaux universitaires de Strasbourg, Strasbourg, France; Frédéric Farizon MD, Service d'orthopédie et traumatologie, Hôpital Nord, Saint-Priest en Jarez, France; Michel Fessy MD, PhD, Hospices Civils de Lyon, Centre Hospitalier LyonSud, Service de Chirurgie Orthopédique Traumatologique et de Médecine du Sport, Centre Hospitalier Lyon Sud, Pierre-Bénite 
2010 to December 2011) were done in 2107 patients (1201 females [57\%] and 906 males [43\%]; median age, 73 years; age range, 17-104 years) at the time of surgery after a median of 11 years (range, 0 day-42 years) after the primary THA. There were 238 of 2107 (11\%) CoC, 148 of 2107 (7\%) metalon-metal (MoM), and 1721 of 2017 (82\%) metal-on-polyethylene (MoP) bearings.

Results The reasons for reoperation differed according to the bearing component: (1) for the MoP reference bearing (odds ratio [OR]; 95\% confidence interval), cup loosening occurred in 698 of 1721 hips (41\%), periprosthetic fracture in 220 of 1721 hips (13\%), and osteolysis in 213 of 1721 hips (12\%); (2) for CoC, cup loosening occurred in 41 of 238 hips (17\%) (OR, 0.31 [0.22-0.43; p $<0.001)$, infection in 39 of 238 hips $(16 \%)(\mathrm{OR}, 1.63$ [1.12-2.37]; $\mathrm{p}=0.01)$, and dislocation in 23 of 238 hips (10\%) (OR, 0.9 [0.57-1.42]; $\mathrm{p}=$ 0.9); (3) for MoM, cup loosening occurred in 28 of 148 hips (19\%) (OR, 0.34 [0.22-0.52]; $\mathrm{p}<0.001$ ), adverse reaction to metallic debris in 26 of 148 hips (18\%) (OR, 18.12 [9.84$33.4]$; $\mathrm{p}<0.001)$, and infection in 16 of 148 hips $(11 \%)(\mathrm{OR}$, 1 [0.59-1.73]; $\mathrm{p}=0.9)$. In comparison with MoP, osteolysis was rarely the reason for revision in $\mathrm{CoC}$ (four of 238 hips [2\%]; OR, 0.12 [0.05-0.33]; $\mathrm{p}<0.001$ ), but this bearing was frequently revised because of iliopsoas irritation (18 of 238 hips [8\%]; OR, 4.9 [2.7-9]; p < 0.001). The time elapsed before revision differed between bearings: median of 3 years

Cedex, France; Xavier Flecher MD, PhD, Department of Orthopaedic Surgery, APHM, Institute for Locomotion, Sainte-Marguerite Hospital, Marseille, France; Myriam Galvin MD, Chirurgie Orthopédique et Traumatologique, Hôpital Gabriel Montpied, Clermont Ferrand, France; François Gaucher MD, Centre hospitalier de Cornouaille, Quimper, France; Fabrice Gaudot MD, Service de Chirurgie Orthopédique, Hôpital Raymond-Poincaré, Garches, France; Louis-Etienne Gayet MD, Service de Chirurgie Orthopédique et Traumatologique, CHU La-Milétrie, Poitiers, France; François Gouin MD, Clinique Chirurgicale de Chirurgie Orthopédique et Traumatologique, Nantes, France; Olivier Guyen MD, PhD, Department of Orthopedic Surgery, Pavillon T, Hôpital Edouard Herriot, Lyon, France; Christophe Hulet MD, PhD, Département d'orthopédie-traumatologie, CHU de Caen, Caen, France; Denis Huten MD, Service de chirurgie orthopédique, CHU Rennes, Rennes, France; Jean-Yves Jenny MD, Centre de Chirurgie Orthopédique et de la Main, University Hospital Strasbourg, Illkirch, France; Matthieu Karoubi MD, Hôpital Cochin, APHP, Université Paris 5, Paris, France; Jean-François Kempf MD, PhD, Service de chirurgie orthopédique et de traumatology, Hôpital de Hautepierre, Hôpitaux universitaires de Strasbourg, Strasbourg, France; Jean-Christophe Lambotte MD, Service de chirurgie orthopédique, CHU Rennes, Rennes, France; Jean-François Lardanchet MD, Service de chirurgie orthopédique, CHU d'Amiens, Amiens, France; Benoit Lebel $\mathrm{MD}, \mathrm{PhD}$, Département d'orthopédie-traumatologie, CHU de Caen, Caen, France; Jean-Paul Levai MD, Chirurgie Orthopédique et Traumatologique, Hôpital Gabriel Montpied, Clermont Ferrand, France; Jean-Baptiste Leymarie MD, Orthopaedic Department, Centre Hospitalier de Versailles, Versailles-Saint Quentin University, Le Chesnay, France; Frédéric Leiber-Wackenheim MD, Service de chirurgie orthopédique, CHU d'Amiens, Amiens, France; Philippe Loriaut MD, Department of Orthopaedic and Sport Surgery, Pitié (range, 3 days to 28 years) for $\mathrm{CoC}$ and 4 years (range, 14 days to 37 years) for MoM versus a median 13 years (range, 0 day to 42 years $)$ for $\mathrm{MoP}(\mathrm{p}<0.001)$. Thirty-seven of the 238 revisions $(16 \%)$ were directly related to ceramic use (ceramic breakage $[n=23]$, squeaking $[n=6]$, impingement $[n=$ 7], incorrect ceramic insert insertion [ $n=1]$ ). No factors were identified that contributed to breakage of the 12 bulk ceramic components (eight heads, four inserts, four of 12 Delta ceramic). No factors were associated with squeaking, iliopsoas irritation, or impingement, but component orientation was not assessed.

Conclusions The reasons and time to first revision differed between $\mathrm{CoC}$ and other bearings. CoC THAs are revised earlier and are sensitive to mechanical problems such as impingement, squeaking, and ceramic rupture that did not disappear with introduction of Delta ceramics and large-diameter $(\geq 36 \mathrm{~mm}$ ) bearings. $\mathrm{CoC}$ was rarely revised for osteolysis, but a high rate of iliopsoas irritation requires further investigation.

Level of Evidence Level III, therapeutic study.

\section{Introduction}

Ceramic-on-ceramic $(\mathrm{CoC})$ bearings were introduced in THA more than 40 years ago [3]. This bearing was

Salpêtrière Hospital, Pierre and Marie Curie University, Paris, France; Philippe Massin MD, Département de Chirurgie Orthopédique, Hôpitaux universitaires Paris Nord Val-de-Seine, Paris, France; Patrice Mertl MD, Service de chirurgie orthopédique, CHU d'Amiens, Amiens, France; Daniel Molé MD, Service de chirurgie orthopédique, Nancy, France; Philippe Oger MD, Orthopaedic Department, Centre Hospitalier de Versailles, Versailles-Saint Quentin University, Le Chesnay, France; Richard Philippe MD, Service de chirurgie orthopédique, Nancy, France; Jean-Louis Polard MD, Service de chirurgie orthopédique, CHU Rennes, Rennes, France; Jean-Louis Prudhon MD, Clinique des Cèdres 21 rue Albert Londres, Echirolles France; Olivier Roche MD, Service de chirurgie orthopédique, Nancy, France; Dominique Saragaglia MD, Academic Department of Orthopaedic Surgery and Sports Trauma, CHU de Grenoble Teaching Hospital Center, South District Hospital, Échirolles, France; Claude Schwartz MD, Nouvelle Clinique des 3 Frontières, Saint Louis, France; Laurent Sedel MD, PhD, Department of Orthopaedic Surgery and Traumatology, AP-HP, Hôpital Lariboisière, Université Paris 7 Denis Diderot, Paris, France; Thierry Siguier MD, Clinique Jouvenet, Paris, France; Grégory Sorriaux MD, Clinique Jouvenet, Paris, France; François Steffann MD, Clinique des Cèdres 21 rue Albert Londres, Echirolles France; Jacques Tabutin MD, Service de Chirurgie Orthopédique et de Traumatologie, Centre Hospitalier de Cannes, Cannes, France; Jérome Taviaux MD, Service de chirurgie orthopédique, CHU d'Amiens, Amiens, France; Simon Teyssédou MD, Service de Chirurgie Orthopédique et Traumatologique, CHU La-Milétrie, Poitiers, France; Emmanuel de Thomasson MD, Institut Mutualiste Montsouris, Paris, France; Philippe Triclot MD, Saint-Grégoire Private Hospital, Saint-Grégoire, France; Anthony Viste MD, PhD, Hospices Civils de Lyon, Centre Hospitalier Lyon-Sud, Service de Chirurgie Orthopédique Traumatologique et de Médecine du Sport, Centre Hospitalier Lyon 
expected to minimize the rate of long-term revisions because of its excellent tribologic properties and generation of inert wear debris [12, 22, 29]. However, concerns about cup fixation emerged because of component hardness that may decrease THA survival [12, 16, 29], even after modern designs were introduced to enhance cementless acetabular fixation [4]. The rate of ceramic breakage has diminished with the introduction of better components and is currently estimated to be below one in 5000 [1, 20, 28]. However, with more frequent use of ceramics, other concerns such as squeaking have emerged with a frequency of $0.5 \%$ to $20 \%$ $[2,5,6,18,27]$. All these limitations expose CoC THAs to reoperation with the 10-year survival rate ranging from $62 \%$ to $97 \%$ [12-17].

Despite greater use of $\mathrm{CoC}$ bearings in THA in the last 10 years, little is known about why this bearing fails. A recent retrospective study [25] of 38 CoC THA revisions found that femoral loosening (13 of 38) was the main reason for reoperation. Historical data also suggest that the main reason for failure of $\mathrm{CoC}$ THA is cup loosening $[12,29]$. Little is known about $\mathrm{CoC}$ revisions from national registries: only $84 \mathrm{CoC}$ hips are included in the Swedish hip registry [33] and only 71 CoC THA revisions are mentioned in the Danish register [35]. Although a large number of $\mathrm{CoC}$ bearings are included in the Australian registry, osteolysis and loosening are combined, confounding these two major issues [32]. In contrast, the reasons for revision of other bearing types have more typically been related to wear issues such as osteolysis in the case of metal-on-polyethylene (MoP) and adverse local tissue reaction in the case of metal-on-metal (MoM) $[8,19,32,33,36]$.

Using a French national study run by the Société Française de Chirurgie Orthopédique et Traumatologique (SoFCOT), we sought to answer the following questions:

Sud, Pierre-Bénite Cedex, France; and Frédéric Zadegan MD, Department of Orthopaedic Surgery and Traumatology, AP-HP, Hôpital Lariboisière, Université Paris 7 Denis Diderot, Paris, France.

H. Migaud ( $₫)$, S. Putman, G. Kern, R. Isida, J. Girard Hôpital Salengro, Lille University Hospital, Place de Verdun, 59037 Lille, France

e-mail: hemigaud@nordnet.fr; h-migaud@chru-lille.fr

N. Ramdane

Department of Biostatistics, CERIM, Université Lille Nord de France, Lille, France

C. P. Delaunay

Clinique de l'Yvette, Longjumeau, France

M. Hamadouche

Hospital Cochin, University of Paris, Paris, France
(1) Do the reasons for first revision differ between $\mathrm{CoC}$ bearings and other bearing couples? (2) Does the time to revision differ between $\mathrm{CoC}$ and other bearing couples? (3) Are there unique reasons for revisions of $\mathrm{CoC}$ bearings?

\section{Patients and Methods}

All members of the SoFCOT and French Hip and Knee Society were invited to participate in the study provided at least 30 revision THAs were performed each year at their facilities. This prospective multicenter cohort study, which started January 1, 2010, was strictly observational without any modification of the participating centers' usual practice. The study was restricted to first revisions of conventional THA or resurfacing and included all such operations performed in 2010 and 2011 (repeat revisions, revision of femoral arthroplasty, and bipolar arthroplasties were excluded). Our data represent $12 \%$ of the revision procedures performed in France. A detailed description of the study can be found in previous publications [8, 11, 28]. In summary, revisions were performed in 2107 patients (1201 females [57\%] and 906 males [43\%]) with a median age of 73 years (range, 17-104 years) at the time of surgery after a median of 11 years (range, 0 day to 42 years) after the primary THA.

Among the included 2107 first THA revisions, there were 238 of 2107 (11\%) CoC THAs, 148 of 2107 (7\%) MoM THAs, and 1721 of 2017 (82\%) MoP THAs (118 crosslinked, 1556 conventional polyethylene, 47 unknown). The primary procedure was done in younger patients for CoC THA (median, 58 years; range, 15-86 years) than for MoP THA (median, 60 years; range, $14-96$ years $)(\mathrm{p}=0.018)$. The primary procedure was done in a higher proportion of males for CoC (126 of 238 [53\%]) than for MoP THA (710 of 1721 [41\%]; $\mathrm{p}=$ 0.002 ) and in more active patients (Devane activity score [9] of 4 or 5) for CoC THA (66 of 234 [28\%]) than for MoP THA (234 of 1673 [14\%]; p < 0.001) (Table 1). In contrast, there was no difference between bearings according to body mass index (Table 1). Osteoarthritis was the main indication for the primary procedure for CoC (152 of 236 [64\%]), MoM (97 of 146 [67\%]), and MoP (1080 of 1705 [63\%]), but the proportion of hips that had THA because of necrosis of the femoral head was higher in the $\mathrm{CoC}$ group (32 of 236 [14\%]) than the MoP group (131 of 1705 [8\%]) (Table 1). Conversely, the proportion of hips that had THA because of dysplasia was higher in MoP THA (230 of 1705 [13\%]) than in CoC THA (18 of 236 [8\%]) (Table 1).

The $\mathrm{CoC}$ bearings were alumina-on-alumina $(\mathrm{Al} / \mathrm{Al})$ in 181 hips (76\%), a Delta ceramic head (CeramTec, Plochingen, Germany) with an alumina insert in three hips 
(1.5\%), an alumina head with a Delta insert in three hips $(1.5 \%)$, and Delta-on-Delta in 51 hips $(21 \%)$. The diameter of the $\mathrm{CoC}$ bearing was $28 \mathrm{~mm}$ in 73 hips (30\%), $32 \mathrm{~mm}$ in 108 hips (45\%), and $36 \mathrm{~mm}$ in 56 hips (24\%) (one unknown). For MoM THA, the diameter was $28 \mathrm{~mm}$ in 63 of 148 hips (43\%), $32 \mathrm{~mm}$ in 16 of 148 hips (11\%), $36 \mathrm{~mm}$ in six of 148 hips (4\%), and larger than $36 \mathrm{~mm}$ in 49 of 148 hips (33\%) (14 unknown). The diameter of MoP THA was $22 \mathrm{~mm}$ in 504 of 1721 hips (29\%), $28 \mathrm{~mm}$ in 1000 of 1721 hips (58\%), $32 \mathrm{~mm}$ in 131 of $1721(8 \%)$, and $36 \mathrm{~mm}$ and larger in 22 of 1721 hips $(1.2 \%)$ (14 unknown) ( $p<0.001)$.

The following variables were recorded for all groups: (1) age at the time of revision and followup of the THA; (2) reasons for revision in detail and then grouping those directly related to ceramic use (impingement, squeaking, ceramic breakage, incorrect ceramic insert insertion) and potentially related to ceramic use (iliopsoas irritation, unexplained pain) from those that were not specific to ceramic use (loosening, infection, instability, periprosthetic fracture, osteolysis, breaking of nonceramic components, surgical technical errors other than those related to insertion of ceramic components). The reasons for revision were compared using MoP bearings $(n=1721)$ as a reference to those of $\mathrm{CoC}$ bearings $(\mathrm{n}=238)$ and MoM bearings $(n=148)$. (3) Finally we assessed the complications related to ceramic use (breakage, squeaking, impingement, iliopsoas irritation, and unexplained pain) as a function of bearing diameter $(<32 \mathrm{~mm}$ and $\geq 32 \mathrm{~mm})$, type of ceramic (alumina or Delta), and diameter of the primary cup.

\section{Statistical Analysis}

Data were collected online at the 30 centers using common software (FileMaker ${ }^{\mathrm{TM}}$ Pro, San Diego, CA, USA). Categorical variables (indication for revision, diameter of the articulation, type of ceramic) were expressed as frequencies and percentages; numerical variables (age, body mass

Table 1. Comparison of the demographics for the three bearing types included in this study

\begin{tabular}{|c|c|c|c|c|}
\hline Demographic & $\begin{array}{l}\text { Ceramic-on-ceramic } \\
(\mathrm{n}=238)\end{array}$ & $\begin{array}{l}\text { Metal-on-metal } \\
(\mathrm{n}=148)\end{array}$ & $\begin{array}{l}\text { Polyethylene bearing } \\
(\mathrm{n}=1721)\end{array}$ & $\mathrm{p}$ value \\
\hline \multicolumn{5}{|l|}{ Sex } \\
\hline Female & $112 / 238(47 \%)^{\mathrm{a}}$ & $75 / 148(51 \%)^{\mathrm{b}}$ & $1011 / 1721(59 \%)$ & $<0.001$ \\
\hline Male & $126 / 238(53 \%)$ & $73 / 148(49 \%)$ & & \\
\hline Age at primary THA (years) Median (range) & $58(15-86)^{\mathrm{d}}$ & $59(15-86)^{\mathrm{e}}$ & $61(14-97)^{\mathrm{f}}$ & 0.0072 \\
\hline Time before revision (years) Median (range) & $3(0.01-28)^{\mathrm{g}}$ & $4(0.04-37)^{\mathrm{h}}$ & $13(0-42)^{\mathrm{i}}$ & $<0.001$ \\
\hline Age at THA revision (years) Median (range) & $63(16-91)^{\mathrm{j}}$ & $63(22-91)^{\mathrm{k}}$ & $74(20-104)^{1}$ & $<0.001$ \\
\hline Diameter of bearing couple (mm) Median (range) & $32(26-36)^{\mathrm{m}}$ & $32(22-56)^{\mathrm{n}}$ & $28(22-52)^{\mathrm{o}}$ & $<0.001$ \\
\hline Body mass index $\left(\mathrm{kg} / \mathrm{m}^{2}\right)$, median(range) & $26(15-59)$ & $26(15-44)$ & $26(14-66)$ & 0.24 \\
\hline \multicolumn{5}{|l|}{ Devane activity score (59 missing values) } \\
\hline One & $13 / 234(6 \%)^{\mathrm{p}}$ & $3 / 141(2 \%)^{\mathrm{q}}$ & $161 / 1673(10 \%)^{\mathrm{r}}$ & $<0.001$ \\
\hline Two & $50 / 234(21 \%)$ & $39 / 141(28 \%)$ & $655 / 1673(39 \%)$ & \\
\hline Three & $105 / 234(45 \%)$ & $48 / 141(34 \%)$ & $623 / 1673(37 \%)$ & \\
\hline Four & $55 / 234(23 \%)$ & $44 / 141(31 \%)$ & $196 / 1673(12 \%)$ & \\
\hline Five & $11 / 234(5 \%)$ & $7 / 141(5 \%)$ & $38 / 1673(2 \%)$ & \\
\hline Indication for primary THA (20 missing values) & $152 / 236(64 \%)^{\mathrm{s}}$ & $97 / 146(67 \%)^{\mathrm{t}}$ & $1080 / 1705(63 \%)^{\mathrm{u}}$ & 0.0089 \\
\hline Osteoarthritis Dysplasia & $18 / 236(8 \%)$ & $18 / 146(12 \%)$ & $230 / 1705(14 \%)$ & \\
\hline Inflammatory disease & $5 / 236(2 \%)$ & $2 / 146(1 \%)$ & $44 / 1705(2 \%)$ & \\
\hline Miscellaneous & $10 / 236(4 \%)$ & $2 / 146(1 \%)$ & $55 / 1705(3 \%)$ & \\
\hline Necrosis of the femoral head & $32 / 236(14 \%)$ & $19 / 146(13 \%)$ & $131 / 1705(8 \%)$ & \\
\hline Trauma & $19 / 236(8 \%)$ & $8 / 146(6 \%)$ & $165 / 1705(10 \%)$ & \\
\hline
\end{tabular}

Results are presented as number (\%) for qualitative variables and as median (range) for quantitative variables; pairwise comparisons were performed using the Bonferroni procedure or the Dwass, Steel, Critchlow-Fligner multiple comparison procedure; a versus b: $p=1 ; a$ versus c: $p=0.0018$; b versus $c: p=0.1656$; versus $e: p=0.9646$; $d$ versus $f: p=0.0182$; e versus $f: p=0.1569 ; g$ versus $h: p=0.1928$; $g$ versus $i$ : $p<$ 0.0001 ; h versus i: $p<0.0001$; versus $k: p=0.8177$; versus $1: p<0.0001$; $k$ versus $1: p<0.0001 ; m$ versus $n: p=0.3513 ; m$ versus $0: p<$ $0.0001 ; n$ versus $0: p<0.0001 ; p$ versus $q: p=0.2331 ; p$ versus $r: p<0.0001 ; q$ versus $r: p<0.0001 ;$ versus $t: p=1 ; s$ versus $u$ : $p=0.0249 ; t$ versus $\mathrm{u}: \mathrm{p}=0.2355$. 
index [BMI], followup) were expressed as median and range. The majority of the primary variables had no missing data (age, sex, reason for revision of the $\mathrm{CoC}$ THA) or less than $3 \%$ missing values (bearing diameter [ $n=29]$, Devane activity level $[n=59]$, indication for primary THA [ $n=20]$, followup of the THA $[\mathrm{n}=51]$ ). Other variables had less than $10 \%$ missing values (BMI [n $=98$ ], cup diameter $[\mathrm{n}=208]$ ). No specific method was used to handle missing data because the missing values were limited and did not affect major variables and also because multivariable analyses were not carried out.

We measured the influence of different variables on $\mathrm{CoC}$ breakage incidence (bearing diameter, bearing material, Devane activity level) using the chi-square test or Fisher's exact test. We explored differences in $\mathrm{CoC}$ breakage according to numerical variables (BMI, cup diameter) using the unpaired Wilcoxon test. Factors associated with revision (cup diameter) were documented for impingement, iliopsoas irritation, and squeaking, but no statistical validation was done because of the limited number of cases. We compared patient characteristics and time to revision in the three bearings of interest (MoP, MoM, and $\mathrm{CoC}$ ) using the chi-square test or Fisher's exact test for qualitative variables and using the Kruskal-Wallis test for quantitative variables. Pairwise comparisons were performed using the Bonferroni correction or the Dwass, Steel, Critchlow-Fligner procedure. To compare the reasons for revision according to the type of bearing components, we used the chi-square test or Fisher's exact test. We also indicated the odds ratio (OR) and $95 \%$ confidence interval relative to the reference polyethylene bearing. The university's statistical department performed all statistics using SAS Version 9.2 and JMP 6.0 (SAS Institute, Cary, NC, USA). Significant $\mathrm{p}$ value was set at $5 \%$.

\section{Results}

The reasons for reoperation differed based on the bearing type (Table 2). For the reference MoP bearing, the reasons for revision in decreasing order were cup loosening in 698 of 1721 hips (41\%), periprosthetic fracture in 220 of 1721 hips (13\%), and osteolysis in 213 of 1721 hips (12\%). For CoC THA, the reasons for revision in decreasing order were cup loosening in 41 of 238 hips (17\%) (OR, 0.31; 95\% confidence interval $[\mathrm{CI}], 0.22-0.43 ; \mathrm{p}<0.001)$, infection in 39 of 238 hips (16\%) (OR, 1.63; 95\% CI, 1.12$2.37 ; \mathrm{p}=0.01)$, and dislocation in 23 of 238 hips (10\%) (OR, 0.9; 95\% CI, 0.57-1.42; p = 0.9) (Table 2). For MoM THA, the reasons for revision were cup loosening in 28 of 148 hips (19\%) (OR, 0.34; 95\% CI, 0.22-0.52; $<<0.001$ ), adverse reaction to metallic debris in 26 of 148 hips (18\%)
(OR, 18.12; 95\% CI, 9.84-33.4; $\mathrm{p}<0.001$ ), and infection in 16 of 148 hips $(11 \%)(\mathrm{OR}, 1 ; 95 \% \mathrm{CI}, 0.59-1.73$; $\mathrm{p}=$ 0.9) (Table 2). In contrast to MoP, osteolysis was rarely the reason for revision in CoC THA (four of 238 hips [2\%]) (OR, 0.12; 95\% CI, 0.05-0.33; $\mathrm{p}<0.001$ ), but this bearing was frequently revised because of iliopsoas irritation (18 of 238 hips [8\%]) (OR, 4.9; 95\% CI, 2.7-9; p < 0.001). Thirty-seven of the 238 revisions $(16 \%)$ were directly related to ceramic use (ceramic breakage $[n=23]$, squeaking $[n=6]$, impingement $[n=7]$, incorrect ceramic insert insertion $[\mathrm{n}=1]$ ), and 23 of $238(10 \%)$ were potentially related to ceramic use (iliopsoas irritation $[\mathrm{n}=$ 18], unexplained pain $[n=5])$. Using the same indications for revision, MoM THA was revised in five of 148 hips (3\%) (squeaking [n $=1]$, impingement $[\mathrm{n}=4]$ ) and 17 of 148 hips $(11 \%)$ (iliopsoas irritation $[n=5]$ and unexplained pain $[\mathrm{n}=12]$ ), whereas MoP THAs were revised in 12 of $1721(0.7 \%)$ (ceramic breakage $[\mathrm{n}=11]$ and impingement $[\mathrm{n}=1])$ and 28 of 1721 hips (2\%) (iliopsoas irritation [ $\mathrm{n}=$ $28]$ and unexplained pain $[\mathrm{n}=10])(\mathrm{p}<0.001$ versus $\mathrm{CoC}$ for specific and specific + potentially related to ceramic use) (Table 2).

The time to revision was different between bearings because the CoC THAs were revised after a median of 3 years (range, 3 days to 28 years) and MoM THAs after a median of 4 years (range, 14 days to 37 years) versus a median of 13 years (range, 0 day to 42 years) for MoP THA ( $p<0.001)$ (Table 3). Noncrosslinked polyethylene bearings were revised later after a median of 13.2 years (range, 0 day to 42 years) than crosslinked polyethylene THAs that were revised after a median of 2 years (range, 1 day to 13 years) ( $\mathrm{p}<0.001$ ). For CoC THA, revision was done within 1 year of insertion in 34 of 233 hips (14\%) and 144 of 233 hips (61\%) were revised within 5 years (time to revision unknown in five hips). For MoM THA, the revision was done within 1 year after insertion in 16 of 147 hips (11\%), and 81 hips (55\%) were revised within 5 years (time to revision unknown in one hip). For MoP THA, the revision was done within 1 year in 183 of 1676 hips (11\%), but only 371 hips (22\%) were revised within 5 years (time to revision unknown in 45 hips) ( $p<0.001)$. CoC THAs were revised earlier than MoP THAs when revision was done because of cup + stem loosening (median, 8 years; range, 0.4-25 years versus median, 15 years; range, $0.03-$ 42 years; $\mathrm{p}<0.001$ ), periprosthetic fracture (median, 5 years; range, $0.03-15$ years versus median, 10 years; range, $0.02-36$ years; $p=0.001$ ), and dislocation (median, 1 year; range, 0.02-17 years versus median, 6 years; range, 0-33 years; $p=0.02$ ), but there was no difference with the numbers available in the time to revision for osteolysis and iliopsoas irritation (Table 3).

Thirty-seven $\mathrm{CoC}$ THA revisions were specifically related to ceramic use (Table 4). Apart from the 11 hips 
Table 2. Reasons for revision by type of bearing (listed in decreasing frequency)

\begin{tabular}{|c|c|c|c|c|}
\hline Reason for revision $(\mathrm{n}=2107)$ & $\begin{array}{l}\text { Polyethylene } \\
\text { bearing }(\mathrm{n}=1721) \\
\text { number }(\%) ; \\
\text { reference group }\end{array}$ & $\begin{array}{l}\text { Ceramic-on-ceramic } \\
(\mathrm{n}=238) \text { number }(\%) \\
\text { OR }(95 \% \mathrm{CI})\end{array}$ & $\begin{array}{l}\text { Metal-on-metal }(\mathrm{n}=148) \\
\text { number }(\%) \text {; OR }(95 \% \mathrm{CI})\end{array}$ & $\mathrm{p}$ value \\
\hline $\begin{array}{l}\text { Cup aseptic loosening }(\mathrm{n}=767) \\
\quad(\text { cup or cup }+ \text { stem })\end{array}$ & $698(41)$ & $41(17) ; 0.31(0.22-0.43)$ & 28 (19); $0.34(0.22-0.52)$ & $\begin{array}{l}<0.001^{*} \\
\quad\left({ }_{\mathrm{a}}^{\mathrm{a}} \mathrm{p}<0.001\right. \\
\left.\quad \mathrm{b}_{\mathrm{p}}<0.001\right)\end{array}$ \\
\hline Periprosthetic fracture $(n=249)$ & $220(13)$ & $21(9) ; 0.66(0.41-1.05)$ & $8(5) ; 0.390(0.19-0.81)$ & $\begin{array}{l}0.0090^{*} \\
\quad\left({ }^{\mathrm{a}} \mathrm{p}<0.0833\right. \\
\quad \mathrm{b} \mathrm{p}=0.0110)\end{array}$ \\
\hline Infection $(\mathrm{n}=240)$ & $185(11)$ & $39(16) ; 1.63(1.12-2.37)$ & $16(11) ; 1.01(0.59-1.73)$ & $\begin{array}{l}0.0362 * \\
\quad(\mathrm{a} p<0.0111 \\
\quad \mathrm{b} p=0.9816)\end{array}$ \\
\hline Osteolysis $(\mathrm{n}=230)$ & $213(12)$ & $4(2) ; 0.12(0.05-0.33)$ & $13(9) ; 0.68(0.38-1.23)$ & $\begin{array}{l}<0.001 * \\
\quad\left({ }^{\mathrm{a}} \mathrm{p}<0.0001\right. \\
\left.\quad{ }_{\mathrm{b}} \mathrm{p}=0.2008\right)\end{array}$ \\
\hline Dislocation $(n=221)$ & $183(11)$ & 23 (10); $0.90(0.57-1.42)$ & $15(10) ; 0.95(0.54-1.65)$ & NS (0.89) \\
\hline Stem aseptic loosening $(n=124)$ & $96(6)$ & $20(8) ; 1.55(0.94-2.57)$ & $8(5) ; 0.97(0.46-2.03)$ & NS $(0.21)$ \\
\hline $\begin{array}{l}\text { Surgical technical error }(\mathrm{n}=64) \\
\text { (malposition, incorrect insert } \\
\text { position, leg length discrepancy, } \\
\text { femoral perforation) }\end{array}$ & $33(2)$ & $22(9) ; 5.21(2.98-9.10)$ & $9(6) ; 3.31(1.55-7.06)$ & $\begin{array}{l}<0.001^{*} \\
\quad\left({ }^{\mathrm{a}} \mathrm{p}<0.001\right. \\
\left.\quad \mathrm{b}_{\mathrm{p}}=0.0019\right)\end{array}$ \\
\hline Iliopsoas irritation $(\mathrm{n}=51)$ & $28(2)$ & $18(8) ; 4.95(2.69-9.09)$ & $5(3) ; 2.11(0.80-5.56)$ & $\begin{array}{l}<0.001 * \\
\quad\left({ }^{\mathrm{a}} \mathrm{p}<0.001\right. \\
\left.\quad{ }_{\mathrm{b}} \mathrm{p}=0.1291\right)\end{array}$ \\
\hline $\begin{array}{l}\text { Miscellaneous }(n=48) \text { (ossification, } \\
\text { ARMD, impingement other than } \\
\text { iliopsoas and prosthetic) }\end{array}$ & $20(1)$ & $2(1) ; 0.72(0.17-3.10)$ & $26(18) ; 18.12(9.84-33.40)$ & $\begin{array}{l}<0.001^{*} \\
\quad\left({ }^{\mathrm{a}} \mathrm{p}=0.6603\right. \\
\left.\quad{ }_{\mathrm{b}} \mathrm{p}<0.001\right)\end{array}$ \\
\hline $\begin{array}{l}\text { Stem or modular neck fracture } \\
\quad(\mathrm{n}=33)\end{array}$ & $\begin{array}{l}23 \text { (10 modular } \\
\text { necks, } 13 \text { stems }) \\
\text { (1) }\end{array}$ & $\begin{array}{l}7 \text { (modular necks) }(3) ; \\
2.24(0.9540-5.2743)\end{array}$ & $\begin{array}{l}3 \text { (modular necks) }(2) ; \\
1.53(0.4543-5.15)\end{array}$ & NS $(0.11)$ \\
\hline Unexplained pain $(\mathrm{n}=27)$ & $10(1)$ & $5(2) ; 3.67(1.24-10.83)$ & $12(8) ; 15.09(6.41-35.57)$ & $\begin{array}{l}<0.001 * \\
\quad\left({ }^{\mathrm{a}} \mathrm{p}=0.0185\right. \\
\left.\quad{ }_{\mathrm{b}} \mathrm{p}<0.001\right)\end{array}$ \\
\hline Bulk ceramic fracture $(n=23)$ & $11(1)$ & $12(5) ; \mathrm{N} / \mathrm{A}$ & $0(0) ; \mathrm{N} / \mathrm{A}$ & $<0.001 *$ \\
\hline Prosthetic impingement $(\mathrm{n}=12)$ & $1(0.06)$ & $7(3) ; 52.12(6.38-425.54)$ & $4(3) ; 47.78(5.31-430.29)$ & $\begin{array}{l}<0.001 * \\
\quad\left({ }^{\mathrm{a}} \mathrm{p}<0.001\right. \\
\left.\quad{ }_{\mathrm{b}} \mathrm{p}<0.001\right)\end{array}$ \\
\hline Ceramic sandwich fracture $(n=11)$ & $0(0)$ & $11(5) ; \mathrm{N} / \mathrm{A}$ & $0(0) ; \mathrm{N} / \mathrm{A}$ & $<0.001 *$ \\
\hline Squeaking $(\mathrm{n}=7)$ & $0(0)$ & $6(3) ; \mathrm{N} / \mathrm{A}$ & $1(1) ; \mathrm{N} / \mathrm{A}$ & $<0.001 *$ \\
\hline
\end{tabular}

Polyethylene bearing is used as a reference to calculate odd ratios (ORs) with $95 \%$ confidence interval; results are presented as number (\%); OR (95\% confidence interval $[\mathrm{CI}]$ ); ORs were calculated using polyethylene as the reference group; $* \mathrm{p}$ values $=$ overall $\left({ }^{\mathrm{a}} \mathrm{p}\right.$ values for ceramic-onceramic versus polyethylene; ${ }^{b} \mathrm{p}$ values for metal-on-metal versus polyethylene); $\mathrm{ARMD}=$ adverse reaction to metallic debris; N/A $=$ not available; NS = nonsignificant.

revised because of ceramic sandwich rupture, there were 12 instances of breakage of the bulk ceramic component (four women, eight men) (Table 4). All breakages occurred in homogeneous bearings (no mixing of alumina and Delta ceramics): eight $\mathrm{Al} / \mathrm{Al}$ bearings (six heads and two inserts) and four Delta/Delta bearings (two heads and two inserts). Those 12 patients had a low activity level on the Devane scale (median, 3; range, 1-5) that did not differ with the number available from other CoC THAs in the study group (median, 3; range, $1-5)(\mathrm{p}=0.4)$. The $\mathrm{BMI}$ of these 12 patients (median, $27 \mathrm{~kg} / \mathrm{m}^{2}$; range, 20-41 $\mathrm{kg} / \mathrm{m}^{2}$ ) did not differ with the number available from those of patients who did not experience ceramic breakage (median, $26 \mathrm{~kg} / \mathrm{m}^{2}$; range, $\left.15-59 \mathrm{~kg} / \mathrm{m}^{2}\right)(\mathrm{p}=0.7)$. The 12 cases of ceramic breakage occurred in various cup diameters: median $52 \mathrm{~mm}$ (range, 50-56 $\mathrm{mm}$ ) for insert breakage and median $58 \mathrm{~mm}$ (range, 48-61 mm) for head breakage versus median $54 \mathrm{~mm}$ (range, 44-64 mm) for ceramic components that did not break $(\mathrm{p}=0.06)$. The six CoC THAs revised because of squeaking had a bearing diameter $\geq 32 \mathrm{~mm}$ (five $32 \mathrm{~mm}$ and one $36 \mathrm{~mm}$ ), whereas five of the seven revisions done because of impingement 
Table 3. Time elapsed (years) before revision for the three bearing types

\begin{tabular}{|c|c|c|c|c|}
\hline Reason for revision $(\mathrm{n}=2107)$ & $\begin{array}{l}\text { Ceramic-on-ceramic } \\
(\mathrm{n}=238)\end{array}$ & $\begin{array}{l}\text { Metal-on-metal } \\
(\mathrm{n}=148)\end{array}$ & $\begin{array}{l}\text { Polyethylene } \\
(\mathrm{n}=1721)\end{array}$ & $\mathrm{p}$ value \\
\hline Cup + stem loosening & $8(0.4-25)^{\mathrm{a}}$ & $7(0.2-35)^{\mathrm{b}}$ & $15(0.03-42)^{\mathrm{c}}$ & $<0.001$ \\
\hline Periprosthetic fracture & $5(0.03-15)^{\mathrm{d}}$ & $7(0.06-37)^{\mathrm{e}}$ & $10(0.02-36)^{\mathrm{f}}$ & 0.0023 \\
\hline Infection & $1.5(0.03-28)^{\mathrm{g}}$ & $4(0.03-12)^{\mathrm{h}}$ & $3(0.02-35)^{\mathrm{i}}$ & 0.0402 \\
\hline Osteolysis & $10(5-21)$ & $8(4-10)$ & $16(6-32)$ & N/A \\
\hline Dislocation & $1(0.02-17)^{\mathrm{j}}$ & $8(0.3-17)^{\mathrm{k}}$ & $6(0-33)^{1}$ & 0.0307 \\
\hline Stem loosening & $4(0.4-17)^{\mathrm{m}}$ & $3(0.7-8)^{\mathrm{n}}$ & $14(0.3-31)^{\mathrm{o}}$ & $<0.001$ \\
\hline Technical error & $2(0.01-10)$ & $2(0.1-3)$ & $1(0.01-25)$ & 0.112 \\
\hline Iliopsoas irritation & $3(0.5-9)$ & $3(1-4)$ & $3(0.5-13)$ & N/A \\
\hline Miscellaneous & $2(0.05-6)$ & $4(1-11)$ & $11(0.01-32)$ & N/A \\
\hline Implant fracture & $2(0.7-3)$ & $9(4-11)$ & $11(0.5-30)$ & N/A \\
\hline Unexplained pain & $5(1-10)$ & $4(1-10)$ & $4(1-18)$ & N/A \\
\hline Bulk ceramic fracture & $2(1-25)$ & - & $11(0.9-25)$ & 0.028 \\
\hline Prosthetic Impingement & $2(1-6)$ & $2(0.3-5)$ & 2 (1 hip) & N/A \\
\hline Ceramic sandwich fracture & $9(4-11)$ & - & - & N/A \\
\hline Squeaking & $3(2-9)$ & 0.2 (1 hip) & - & N/A \\
\hline Total & $3(0.01-28)^{\mathrm{p}}$ & $4(0.03-37)^{\mathrm{q}}$ & $13(0-42)^{\mathrm{r}}$ & $<0.001 *$ \\
\hline
\end{tabular}

Pairwise comparisons were performed using the Bonferroni procedure or the Dwass, Steel, Critchlow-Fligner multiple comparison procedure; a versus $b: p=0.4329$; a versus $c: p<0.0001 ; b$ versus $c: p<0.0001 ; d$ versus $e: p=0.3586 ; d$ versus $f: p=0.0018$; e versus f: $p=0.7022 ; g$ versus h: $p=0.2334$; g versus i: $p=0.0377$; $h$ versus i: $p=0.8381 ; j$ versus $k: p=0.0566 ; j$ versus $1: p=0.0294 ; k$ versus $1: p=0.9645 ; m$ versus $n: p=$ $0.6945 ; \mathrm{m}$ versus $\mathrm{o}: \mathrm{p}=0.0003 ; \mathrm{n}$ versus $\mathrm{o}: \mathrm{p}=0.0006 ; \mathrm{p}$ versus $\mathrm{q}: \mathrm{p}=0.1928 ; \mathrm{p}$ versus $\mathrm{r}: \mathrm{p}<0.0001 ; \mathrm{q}$ versus $\mathrm{r}: \mathrm{p}<0.0001 ; \mathrm{N} / \mathrm{A}=\mathrm{not}$ applicable.

Table 4. Characteristics of 37 revisions directly related to ceramic use

\begin{tabular}{|c|c|}
\hline Reasons & Bearing type and diameter of bearing and cup being revised \\
\hline $\begin{array}{l}\text { Ceramic head rupture* } \\
\quad(\mathrm{n}=8)\end{array}$ & $\begin{array}{l}6 \mathrm{Al} / \mathrm{Al}: 3 \text { in } 28 \mathrm{~mm} \text { (cup diameters were } 48 \mathrm{~mm}, 56 \mathrm{~mm} \text {, and } 60 \mathrm{~mm} \text { ), } 2 \text { in } 32 \mathrm{~mm} \text { (cup diameters were } 54 \mathrm{~mm} \\
\text { and NA), } 1 \text { in } 36 \mathrm{~mm} \text { (cup was } 60 \mathrm{~mm} \text { ) } \\
2 \text { Delta/Delta: } 1 \text { in } 32 \mathrm{~mm} \text { (cup was } 58 \mathrm{~mm} \text { ), } 1 \text { in } 36 \mathrm{~mm} \text { (cup was } 60 \mathrm{~mm} \text { ) }\end{array}$ \\
\hline Insert rupture* $(n=4)$ & $\begin{array}{l}2 \mathrm{Al} / \mathrm{Al} \text { : one in } 32 \mathrm{~mm}(\operatorname{cup} 50 \mathrm{~mm}) \text { and one in } 36 \mathrm{~mm}(\operatorname{cup} 56 \mathrm{~mm}) \\
2 \mathrm{Delta} / \text { Delta: one in } 28 \mathrm{~mm}(\operatorname{cup} 52 \mathrm{~mm}) \text { and one in } 36 \mathrm{~mm}(\text { cup } 52 \mathrm{~mm})\end{array}$ \\
\hline $\begin{array}{l}\text { Ceramic sandwich fracture } \\
\quad(\mathrm{n}=11)\end{array}$ & $\mathrm{Al} / \mathrm{Al}$ sandwich, all $28 \mathrm{~mm}$ \\
\hline Squeaking $(n=6)$ & $6 \mathrm{Al} / \mathrm{Al}(5 \mathrm{in} 32 \mathrm{~mm}$ and 1 in $36 \mathrm{~mm})$ \\
\hline $\begin{array}{l}\text { Prosthetic impingement } \\
\quad(\mathrm{n}=7)\end{array}$ & $\begin{array}{l}2 \mathrm{Al} / \mathrm{Al} 28 \mathrm{~mm} \\
1 \mathrm{Al} / \mathrm{Al} 32 \mathrm{~mm} \\
1 \mathrm{Delta} / \text { Delta } 32 \mathrm{~mm} \\
3 \text { Delta/Delta } 36 \mathrm{~mm}\end{array}$ \\
\hline Incorrect insert introduction & $1 \mathrm{Al} / \mathrm{Al} 32 \mathrm{~mm}$ \\
\hline
\end{tabular}

* Cup diameter indicated in cases of ceramic component breakage; $\mathrm{Al} / \mathrm{Al}=$ alumina-on-alumina; $\mathrm{NA}=$ not available.

had a bearing diameter $\geq 32 \mathrm{~mm}$ (two $28 \mathrm{~mm}$, two 32 $\mathrm{mm}$, and three $36 \mathrm{~mm}$ ) (Table 4). Revision because of iliopsoas irritation occurred with a higher frequency in CoC THA (18 of 238 [8\%]), whereas it was rare in MoM THA (five of 148 [3\%]) and uncommon in MoP THA (28 of 1721 [2\%]) ( $\mathrm{p}<0.001)$ (Table 2). Among the CoC
THA group, the cups revised because of iliopsoas irritation had a smaller cup diameter (median, $51 \mathrm{~mm}$; range, 46-58 mm versus $54 \mathrm{~mm}$; range, 44-64 mm). Likewise, seven of the $18 \mathrm{CoC}$ hips revised because of iliopsoas irritation had a 28-mm bearing diameter (seven $32 \mathrm{~mm}$ and four $36 \mathrm{~mm}$ ). 


\section{Discussion}

Despite widespread use of $\mathrm{CoC}$ in THA during the past 10 years, little is known about why revisions are performed and the time elapsed before revision. In the current study, cup loosening was the most common reason for revision of the three bearings. However, $\mathrm{CoC}$ was associated with a lower proportion of cup loosening than MoP (OR, 0.31; 95\% CI, 0.22-0.43). Osteolysis, which was the third most common reason for MoP revision (12\%), was almost sixfold less frequent for $\mathrm{CoC}(2 \%)$ (OR, 0.12; 95\% CI, 0.050.33). The CoC and MoM THAs were revised after a shorter followup (median, 3 and 4 years, respectively) than MoP THA (median, 13 years). Finally, CoC revisions were performed for ceramic-related reasons (ceramic breakage, squeaking, impingement, and incorrect ceramic insertion) in $16 \%$ (37 of 238), whereas these reasons were encountered in 3\% (five of 148) of MoM THAs and $0.7 \%$ (11 of 1721) of MoP THAs.

Although this study involves the largest known cohort of CoC THA revisions, it has several limitations: (1) We have little knowledge of the population in which the primary CoC THA was performed. This issue mainly limits the comparison between different bearings; nevertheless, this large cohort provides an accurate snapshot of the reasons for revision that may affect the different bearings. (2) Data from the Colas et al. [7] study can be used as a denominator to weight our results. The Colas et al. study indicates that approximately 35,000 $\mathrm{CoC}$ THAs were done annually in France over the last 5 years. Because our study group represents $12 \%$ of the revisions done in France, one may estimate that $1983 \mathrm{CoC}$ THAs are revised each year, which results in a $5 \% \mathrm{CoC}$ revision rate $(1963$ of 35,000$)$. However, this calculation is debatable because only 30 centers participated in our study (with some variations between centers) and the CoC hips revised had a very large followup range (1-28 years), which is beyond the inclusion limits of the Colas study and raises concerns when trying to aggregate these data to produce a denominator. In addition, Colas et al. [7] included only THAs done for osteoarthritis in patients older than 40 years, which is different from our study. (3) Despite this being a prospective study, some variables had missing values; but those variables were missing at a rate below $1 \%$ or were not related to major variables. (4) This was a prospective multicenter survey; therefore, including different bearing designs may limit our conclusions. However, this study was designed primarily to compensate for the lack of a French national registry; from that point of view, it provides data with comparable values. (5) We have no data regarding implant orientation and ceramic component retrievals that may influence the rate and the reasons for revision. However, this issue was beyond the scope of our study and is also a limitation of national registries. (6) We have no data on the outcome of the revision THA because this study was not designed to assess the outcomes of $\mathrm{CoC}$ THA revisions but the reasons for revision of $\mathrm{CoC}$ bearings. (7) Finally, we did not perform multivariable analyses to explain the reasons for revision because the sample size was not sufficiently high to consider all reasons and no clear grouping was possible.

$\mathrm{CoC}$ bearings were identified as being at risk of reoperation in the British-Wales Registry [17] and health insurance databases [7, 19]. Our study was not designed to confirm such data, because the initial population was not known. However, we found that $\mathrm{CoC}$ revisions were rarely done for osteolysis in contrast to other bearing types $[17,19]$. Our findings suggest that acetabular fixation is a main issue whether or not the bearing includes ceramic components, despite improvement in cementless fixation $[12,15,29,30]$. The fixation of $\mathrm{CoC}$ cementless cups has been improved using modern porous coatings $[4,13,14,30]$ but remains a weak point of this bearing, particularly when considering the low rate of osteolysis that, contrary to MoP, did not contribute to cup loosening. Our results differ from the study by Porat et al. [27] that identified femoral loosening as the main reason for revision of CoC THA (13 of 38 [34\%]). After revisions for infection $(\mathrm{n}=39)$, revisions directly related to ceramic use (including impingement, squeaking, ceramic breakage, and incorrect ceramic insertion) were the third most common reason for revision in our study $(\mathrm{n}=37)$ (Table 2). Breakage of ceramic-embedded inserts was the indication for revision in 11 hips. Our study is consistent with previous reports on this design [23,31], which was removed from the market because of a high rate of late rupture of the embedded ceramic insert (the brittle ceramic insert was exposed to micromotion and ruptured when being inserted in a deformable plastic insert) [23,31]. We cannot explain the higher rate of CoC THA revision because of infection (OR, 1.63 [1.12-2.37] versus MoP) despite this complication being mostly observed after large-diameter head MoM revisions [36]. Our study reported 39 of 238 revisions because of infection (16\%), whereas the Danish hip register reports only 8\% (six of 71) [35] and the Australian register less than $1 \%$ cumulative incidence revision because of infection at 10 years [32]. These infections were observed in our study despite the $\mathrm{CoC}$ population being younger and more active than the MoP group. Iliopsoas irritation was a common indication for $\mathrm{CoC}$ revision (18 of 238 [8\%]; OR, 4.95 [2.69-9] versus MoP) as reported by Yeung et al. [37] (three of nine [33\%]), but not by Porat et al. [27] (one of 38 [3\%]). This was a paradoxical finding because the revisions for iliopsoas irritation were performed in cups with a smaller diameter and in bearings whose diameter was comparable to other $\mathrm{CoC}$ revisions. We believe that 
iliopsoas irritation may reveal a $\mathrm{CoC}$ bearing dysfunction (as a result of release of metallic debris by impingement and/or by chronic joint swelling) instead of true iliopsoas irritation. This symptom should be explored further when it occurs with CoC bearings.

The current study highlighted that $\mathrm{CoC}$ bearings were likely to be revised after a short period of time: 61\% (144 of 233) were revised within 5 years of insertion against only 22\% (371 of 1676) of MoP THAs. This is an important finding because the time to revision of CoC THA was not mentioned in previous studies [27] or easy to extract from registries (the Australian register mentioned 2109 of 65,114 CoC THA revisions [3.2\%] but not the revision rate before 5 years) [32]. Our results are in accordance with the Danish register indicating that 63 of 71 (88\%) CoC THAs were revised before 5 years of followup [35]. This issue suggests that CoC THAs are technically demanding to use [26]. To summarize, CoC and MoM were revised after the same amount of time, but CoC THAs were revised earlier than MoP because of cup and stem loosening, periprosthetic fractures, dislocations, and infection (Table 3). Although the frequency of revision because of dislocation did not differ between $\mathrm{CoC}$ and MoP (OR, 0.9 [0.57-1.42]), they occurred earlier in $\mathrm{CoC}$ THA (median, 1 year versus 6 years); this issue could be linked to late dislocation of MoP related to wear [32]. Likewise, although the rate of revision because of periprosthetic fractures did not differ between $\mathrm{CoC}$ and MoP (OR, 0.66 [0.41-1.05]) (despite the CoC population being younger), these fractures occurred earlier (median, 5 years versus 10 years). This could be related to a higher activity level in patients receiving the $\mathrm{CoC}$ THA that may increase the risk of trauma versus fractures related to osteoporosis in older patients. Despite osteolysis being rare after CoC THA, it was not revised later than MoP based on the number available. Revision because of cup loosening occurred earlier in $\mathrm{CoC}$ and MoM versus MoP, probably because of the poor tolerance of hard bearings when cup loosening occurs, particularly in the context of significant cup movement.

The current study identified reasons that were specifically associated with CoC revisions. In 16\% (37 of 238) of $\mathrm{CoC}$ hips, ceramic-specific reasons (ceramic breakage, squeaking, impingement, and incorrect ceramic insertion) were the third reason for revision after cup loosening and infection. We were not able to find variables related to breakage of ceramic components (BMI, activity level, cup and head diameter) (Table 4). This differs from the Traina et al. [34] and Elkins et al. [10] studies in which obesity and cup malpositioning were found to contribute to breakage. This study was not designed to provide data regarding cup orientation, which may explain why none of the factors investigated were associated with bulk ceramic rupture considering component orientation as a cofounding factor. The introduction of Delta ceramic was supposed to reduce the risk of ceramic fracture to near zero [13, 25], but four of the 12 instances of bulk ceramic components breakage involved Delta components (two heads, two inserts), making this argument questionable. Likewise, revisions because of impingement were done independent of the bearing diameter, suggesting that use of $36-\mathrm{mm} \mathrm{CoC}$ bearings does not prevent impingement. This finding is different than the ones from a retrieval study that found the head-neck ratio to affect the occurrence of impingement [24]. However, we have no data on the cup position or head-neck ratio in our study; this may explain the absence of a bearing diameter effect. Our study also found that $\mathrm{CoC}$ THAs revised because of squeaking used a bearing diameter $\geq 32 \mathrm{~mm}$, despite most impingement cases being observed in small-diameter bearings [5, 21].

$\mathrm{CoC}$ bearings are revised earlier after implantation than MoP THAs, mainly because of cup and stem fixation failures and complications directly related to ceramic use such as breakage, squeaking, and incorrect ceramic insertion. This last issue, which is mostly under surgeon control, suggests that surgeons must be meticulous when performing CoC THA. The use of Delta components and of bearings larger or equal to $36 \mathrm{~mm}$ does not prevent ceramic-specific complications (prosthetic impingement, squeaking, head rupture). In contrast, osteolysis is rarely an indication for $\mathrm{CoC}$ bearing revision (almost sixfold less than MoP THA). This study reveals that performing $\mathrm{CoC}$ THA is a technically demanding procedure and provides evidence that cementless cup fixation in CoC THA must be improved, because fixation failure remains the most common reason for ceramic bearing THA revision. Further studies are needed to investigate the high frequency of revision because of iliopsoas irritation.

Acknowledgments We thank all the orthopaedic surgeons from the 30 hospitals who participated in this project.

\section{References}

1. Allain J, Roudot-Thoraval F, Delecrin J, Anract P, Migaud H, Goutallier D. Revision total hip arthroplasty performed after fracture of a ceramic femoral head. A multicenter survivorship study. J Bone Joint Surg Am. 2003;85:825-830.

2. Baek SH, Kim WK, Kim JY, Kim SY. Do alumina matrix composite bearings decrease hip noises and bearing fractures at a minimum of 5 years after THA? Clin Orthop Relat Res. 2015;473:3796-3802.

3. Boutin P. Total arthroplasty of the hip by fritted aluminum prosthesis. Experimental study and 1st clinical applications. Orthop Traumatol Surg Res. 2014;100:15-21.

4. Boyer P, Huten D, Loriaut P, Lestrat V, Jeanrot C, Massin P. Is alumina-on-alumina ceramic bearings total hip replacement the right choice in patients younger than 50 years of age? A 7- to 
15-year follow-up study. Orthop Traumatol Surg Res. 2010;96:616-622.

5. Chevillotte C, Trousdale RT, An KN, Padgett D, Wright T. Retrieval analysis of squeaking ceramic implants: are there related specific features? Orthop Traumatol Surg Res. 2012;98:281-287.

6. Cogan A, Nizard R, Sedel L. Occurrence of noise in alumina-onalumina total hip arthroplasty. A survey on 284 consecutive hips. Orthop Traumatol Surg Res. 2011;97:206-210.

7. Colas S, Collin C, Piriou P, Zureik M. Association between total hip replacement characteristics and 3-year prosthetic survivorship: a population-based study. JAMA Surg. 2015;150:979-988.

8. Delaunay C, Hamadouche M, Girard J, Duhamel A, SoFCOT Group. What are the causes for failures of primary hip arthroplasties in France? Clin Orthop Relat Res. 2013;471:3863-3869.

9. Devane PA, Horne JG, Martin K, Coldham G, Krause B. Threedimensional polyethylene wear of a press-fit titanium prosthesis. Factors influencing generation of polyethylene debris. J Arthroplasty. 1997;12:256-266.

10. Elkins JM, Pedersen DR, Callaghan JJ, Brown TD. Do obesity and/or stripe wear increase ceramic liner fracture risk? An XFEM analysis. Clin Orthop Relat Res. 2013;471:527-536.

11. Girard J, Kern G, Migaud H, Delaunay C, Ramdane N, Hamadouche M; SoFCOT. Primary total hip arthroplasty revision due to dislocation: prospective French multicenter study. Orthop Traumatol Surg Res. 2013;99:549-553.

12. Hamadouche M, Boutin P, Daussange J, Bolander ME, Sedel L. Alumina-on-alumina total hip arthroplasty: a minimum 18.5-year follow-up study. J Bone Joint Surg Am. 2002;84:69-76.

13. Hamilton WG, McAuley JP, Blumenfeld TJ, Lesko JP, Himden SE, Dennis DA. Midterm results of Delta ceramic-on-ceramic total hip arthroplasty. J Arthroplasty. 2015;30(Suppl):110-115.

14. Hannouche D, Zaoui A, Zadegan F, Sedel L, Nizard R. Thirty years of experience with alumina-on-alumina bearings in total hip arthroplasty. Int Orthop. 2011;35:207-213.

15. Hernigou P, Homma Y, Pidet O, Guissou I, Hernigou J. Ceramicon-ceramic bearing decreases the cumulative long-term risk of dislocation. Clin Orthop Relat Res. 2013;471:3875-3882.

16. Hernigou P, Zilber S, Filippini P, Poignard A. Ceramic-ceramic bearing decreases osteolysis: a 20 -year study versus ceramicpolyethylene on the contralateral hip. Clin Orthop Relat Res. 2009;467:2274-2280.

17. Jameson SS, Baker PN, Mason J, Rymaszewska M, Gregg PJ, Deehan DJ, Reed MR. Independent predictors of failure up to 7.5 years after 35,386 single-brand cementless total hip replacements: a retrospective cohort study using National Joint Registry data. Bone Joint J. 2013;95:747-757.

18. Keurentjes JC, Kuipers RM, Wever DJ, Schreurs BW. High incidence of squeaking in THAs with alumina ceramic-on-ceramic bearings. Clin Orthop Relat Res. 2008;466:1438-1443.

19. Khatod M, Cafri G, Namba RS, Inacio MC, Paxton EW. Risk factors for total hip arthroplasty aseptic revision. $J$ Arthroplasty. 2014;29:1412-1417.

20. Koo KH, Ha YC, Kim SY, Yoon KS, Min BW, Kim SR. Revision of ceramic head fracture after third generation ceramic-onceramic total hip arthroplasty. J Arthroplasty. 2014;29:214-218.

21. Kuo F-C, Liu H-C, Chen W-S, Wang JW. Ceramic-on-ceramic total hip arthroplasty: incidence and risk factors of bearing surface-related noises in 125 patients. Orthopedics. 2012;35:e15811585 .
22. Lerouge S, Huk O, Yahia L, Witvoet J, Sedel L. Ceramic-ceramic and metal-polyethylene total hip replacements: comparison of pseudomembranes after loosening. J Bone Joint Surg Br. 1997;79:135-139.

23. Lopes R, Philippeau JM, Passuti N, Gouin F. High rate of ceramic sandwich liner fracture. Clin Orthop Relat Res. 2012;470:17051710.

24. Marchetti E, Krantz N, Berton C, Bocquet D, Fouilleron N, Migaud H, Girard J. Component impingement in total hip arthroplasty: frequency and risk factors. A continuous retrieval analysis series of 416 cup. Orthop Traumatol Surg Res. 2011;97:127-133.

25. Massin P, Lopes R, Masson B, Mainard D; French Hip \& Knee Society (SFHG). Does Biolox Delta ceramic reduce the rate of component fractures in total hip replacement? Orthop Traumatol Surg Res. 2014;100(Suppl):S317-321.

26. McAuley JP, Dennis DA, Grostefon J, Hamilton WG. Factors affecting modular acetabular ceramic liner insertion: a biomechanical analysis. Clin Orthop Relat Res. 2012;470:402-409.

27. Porat M, Parvizi J, Sharkey PF, Berend KR, Lombardi AV Jr, Barrack RL. Causes of failure of ceramic-on-ceramic and metalon-metal hip arthroplasties. Clin Orthop Relat Res. 2012;470: 382-387.

28. Reina N, Delaunay C, Chiron P, Ramdane N, Hamadouche M; SoFCOT. Infection as a cause of primary total hip arthroplasty revision and its predictive factors. Orthop Traumatol Surg Res. 2013;99:555-561.

29. Rousseau MA, Le Mouel S, Goutallier D, Van Driessche S. Long-term results of alumina-on-alumina total hip arthroplasty. Rev Chir Orthop Reparatrice Appar Mot. 2004;90:741-748.

30. Sugano N, Takao M, Sakai T, Nishii T, Miki H, Ohzono K. Eleven- to 14-year follow-up results of cementless total hip arthroplasty using a third-generation alumina ceramic-on-ceramic bearing. J Arthroplasty. 2012;27:736-741.

31. Szymanski C, Guériot $S$, Boniface $O$, Deladerrière JY, Luneau $S$, Maynou C. Sandwich type ceramic liner fracture rate with the Atlas III ${ }^{\mathrm{TM}}$ socket: a study of 144 primary total hip replacements at a mean 74 months' follow-up. Orthop Traumatol Surg Res. 2011;97:494-500.

32. The Australian hip register 2015 report. Australian Orthopaedic Association National Joint Replacement Registry. Available at: https://aoanjrr.sahmri.com/documents/10180/217745/Hip\%20and\% 20Knee\%20Arthroplasty. Accessed March 2016.

33. The Swedish Hip Arthroplasty Register. Annual Report 2013. Available at: http://www.shpr.se/Libraries/Documents/Annual Report_2013-04-1_1.sflb.ashx. Accessed March 2016.

34. Traina F, De Fine M, Bordini B, Toni A. Risk factors for ceramic liner fracture after total hip arthroplasty. Hip Int. 2012;22:607614.

35. Varnum C, Pedersen AB, Kjærsgaard-Andersen P, Overgaard S. Comparison of the risk of revision in cementless total hip arthroplasty with ceramic-on-ceramic and metal-on-polyethylene bearings. Acta Orthop. 2015;86:477-84.

36. Wyles CC, Van Demark RE 3rd, Sierra RJ, Trousdale RT. High rate of infection after aseptic revision of failed metal-on-metal total hip arthroplasty. Clin Orthop Relat Res. 2014;472:509-516.

37. Yeung E, Bott PT, Chana R, Jackson MP, Holloway I, Walter WL, Zicat BA, Walter WK. Mid-term results of third-generation alumina-on-alumina ceramic bearings in cementless total hip arthroplasty: a ten-year minimum follow-up. J Bone Joint Surg Am. 2012;94:138-144. 